\title{
Alimentación de estudiantes de pregrado chilenos en el contexto de la modernidad alimentaria
}

\author{
Nutritional habits of chilean university \\ students in the context of \\ alimentary modernity
}

\begin{abstract}
The nutritional habits in Chile, has been affected by the "alimentary modernity". This phenomenon is understood as the transformation of what we eat - how food products are produced, distributed, prepared and consumed - as a consequence of food industrialization, economy and mass media globalization. This process has generated many changes in lifestyle with substantial differences depending on the context in which they operate socioeconomic grounds, age and gender. This article is based on a study undertook in Santiago of Chile from 2008 to 2010, through qualitative methodology. It explores university student's perception of their diet focusing on their relationship with food and their bodies. The main results and conclusions show that the university students feel discomfort with their nutritional habits, mainly the women, students who live alone and who have scanty money for their personal expenses.
\end{abstract}

Key words: Nutritional habits; perceptions; young; university; discomfort.
María Sol Anigstein

Facultad de Ciencias Sociales, Universidad de Chile, Santiago, Chile.

Dirigir la correspondencia a: Profesora María Sol Anigstein Facultad de Ciencias Sociales, Universidad de Chile

Av. Ignacio Carrera Pinto 1045, Nuñoa. Santiago, Chile. Teléfono: 8-5207593

E-mail: sol.anigstein@gmail.com

Este trabajo fue recibido el 9 de Abril de 2013 y aceptado para ser publicado el 5 de Julio de 2013.

\section{INTRODUCCIÓN}

El sentido común indica que una buena alimentación conlleva una buena salud. En Chile, actualmente la alimentación aparece como un problema, vinculada al hecho de que a pesar de haber superado la desnutrición por escasez, se ha avanzado en otro tipo de malnutrición, provocada por una alimentación desequilibrada, con un alto consumo de azúcar y grasas, que ha generado altos índices de obesidad y enfermedades crónicas. En respuesta a dicha situación se han creado programas, campañas y movimientos que no han logrado detener el avance del sobrepeso y la obesidad, cuyos valores han aumentado en mayores de 15 años en Chile desde un $61 \%$ a un $67 \%$ entre 2003 y $2010(1,2)$.

Tales transformaciones se enmarcan en lo que se ha llamado la transición alimentaria y epidemiológica, o lo que Kain et al. (3), Ilaman post transición alimentaria y epidemiológica, que es una transformación en los hábitos de las personas a consecuencia de un aumento en los ingresos, cambio de los precios relativos de alimentos, mayor tecnología alimentaria y nuevas estrategias de distribución. Se trata de un proceso que ha venido transformado tanto a los seres humanos como a los ambientes socioculturales y ecológicos con los que estos interactúan $(4,5)$.

\begin{abstract}
Varias investigaciones abordan la transición alimentaria a manera de catástrofe. En el caso de Chile se refieren a la disminución de la actividad física y las diferentes maneras de enfocar tal "problema", así como las intervenciones que se han realizado desde la política pública (6); del bajo consumo de frutas y verduras en la población local y de la necesidad de realizar campañas educativas para revertir dicha situación (7); baja ingesta de pescados y la alta prevalencia de la obesidad en escolares en el país (8); alta prevalencia de obesidad y poca actividad física en escolares (3); necesidad de generar una política pública para el control del consumo de golosinas por parte de los niños (9); deficiencia de la canasta básica y la pirámide alimentaria definida para el país en algunos elementos esenciales cuando se la compara con la norma europea (10).

Fischler (11) propone que para el comensal contemporáneo los rígidos protocolos de cómo, cuándo, qué y dónde comer se han distendido, y se ha operado una pérdida de la gramática compartida (gastro-anomía) con la cual los individuos clasificaban y eran a su vez clasificados cuando seleccionaban, preparaban y consumían alimentos. Los individuos se enfrentarían entonces, sin muchas herramientas para su administración, a las múltiples fuentes de información, de discursos culinarios, de guías de nutrición, de libros de recetas
\end{abstract}


y de regímenes que están disponibles para ser utilizadas e incorporadas a la visión del mundo que las personas esgrimen para, por ejemplo decidir cuestiones alimentarias (12).

En este escenario el comensal contemporáneo, omnívoro por excelencia, ha ido configurando una manera de alimentarse de tipo vagabunda (11) facilitada por una alimentación solitaria, la gran cantidad de oferta y la realización de las comidas mayoritariamente fuera del hogar.

El objetivo de la investigación cuyos resultados se presentan es poner en evidencia aquello que está orientando las apreciaciones, evaluaciones y percepciones que tienen los jóvenes estudiantes de pregrado respecto de su alimentación y los alimentos, bajo el supuesto que las selecciones que el omnívoro contemporáneo realiza responden a una serie de valores y marcos de sentido ${ }^{1}$ que resultan de vital importancia para comprender las decisiones respecto de la alimentación, la relación que con ésta establecen y el bienestar que les proporciona.

\section{SUJETOS Y MÉTODOS}

La investigación que aquí se presenta consistió en un estudio de caso realizado entre el 2008 y el 2010 en el Campus Juan Gómez Millas de la Universidad de Chile ubicado en la Ciudad de Santiago.

Se realizaron 6 grupos focales de manera exploratoria con estudiantes de las distintas facultades o programas (ciencias sociales, filosofía y humanidades, artes, ciencias, comunicación e imagen y bachillerato), siendo la pertenencia a cada unidad académica el único criterio de selección. Sobre la base del análisis de los grupos focales se establecieron los criterios de selección para 6 entrevistas en profundidad. Los criterios fueron sexo, facultad o programa, tipo de régimen y tipo de residencia, configurando una muestra de tipo estructural, de manera generar representación de la diversidad presente (13). La tercera técnica que se utilizó es la observación simple de manera de complementar. En la tabla 1 se presenta la muestra de los grupos focales y en la tabla 2 la estructuración de la muestra de las entrevistas en profundidad.

Se realizó un análisis cualitativo con apoyo del software de análisis de datos cualitativos Atlas.ti 5.0. El análisis se llevó a cabo en dos etapas. En la primera se analizaron los grupos focales, cuyos resultados constituyeron la guía para el paso siguiente. La segunda de análisis fue llevada a cabo luego de la realización de las entrevistas en profundidad e incluyó el material transcrito proveniente de ambas técnicas, las que fueron analizadas retomando algunos puntos de la primera unidad hermenéutica, pero incluyendo codificación emergente.

\section{RESULTADOS}

Se han identificado cuatro conceptos o marcos de sentido en torno a los cuales se ordenan las apreciaciones sobre la alimentación de los estudiantes del caso estudiado.

\section{a. Alimentación ideal}

La idea de alimentación ideal aparece esbozada en la mayoría de los discursos registrados como un horizonte utópico al que todas/todos aspiran, siendo un modelo a seguir, al cual intentan ajustar su alimentación las/los jóvenes participantes con más o menos éxito.

Cuando se les preguntó de manera directa cuál sería para ellos y ellas una alimentación ideal, la respuesta circuló por unos pocos tópicos: la variedad, el orden, el equilibrio, la estabilidad en los horarios, el espacio de relajo, la moderación en relación a las cantidades, lo sano y el tiempo para preparar y consumir alimentos, es decir, lo casero. Aquí no hubo diferencias que pudieran ser remitidas a discursos de género, tipo de residencia o régimen alimentario.

La alimentación ideal, cuando se refiere al orden y estabilidad en los horarios contempla al desayuno como necesario, al almuerzo como la comida más importante del día y a la idea de que no es bueno ingerir alimentos entre comidas, pero tampoco dejar pasar muchas horas en ayunas. La variedad, el equilibrio y la moderación se vinculan a la ideología alimentaria propugnada por el discurso nutricional y biomédico, según el cual hay que comer de todos los grupos alimentarios equilibrando a la manera que lo prescribe la pirámide alimentaria (5).

La alimentación ideal podría ser representada por dos imágenes que aparecieron con frecuencia para ilustrar lo que los participantes en la investigación entendían por ésta.

La primera de las imágenes es la de la comida casera, que en la mayoría de los casos remitía a los tiempos en que cursaban la educación media, antes del ingreso a la universidad y que tenía una relación muy cercana con el cuidado materno (mucho más que paterno o de cualquier otro miembro de la familia como puede ser una abuela, una tía o un/a hermana/o mayor). La comida casera es entendida como sana, lo que desde la idea de principio de incorporación alude a lo conocido y familiar que ésta resulta (11), y a la menor potencialidad de provocar ansiedades. La idea de

\section{TABLA 1}

Muestra grupos focales

Facultad, instituto o programa

Ciencias Sociales

Filosofía y Humanidades

Bachillerato

Comunicación e imagen

Artes

Ciencias

Número de participantes

7

8

8

6

7

6

1 Entendidos como los conceptos claves que orientan apreciaciones sobre la alimentación y los mismos alimentos 
comida casera está fuertemente homologada a la comida típica chilena. A este ideal alimentario lo llamaremos "Ideal tradicional de alimentación".

"el almuerzo, definitivamente acá es el mejor, es como lo más sano, porque es una comida casera" (Focus Periodismo).

La otra imagen que aparecía en la idea de alimentación ideal es lo sano, entendido como lo liviano no sólo en calorías sino que también en cantidad. Se estima que las cantidades deben ser controladas, siendo entonces una alimentación poco densa y parcelada o racionada en pequeñas porciones la que se vislumbra como ideal. Debe ser consumida de manera ordenada y sin excesos. Una alimentación ideal, sería una alimentación liviana en calorías y en cantidad, ordenada y que sea capaz de dar paso al cuerpo ideal, un cuerpo sano, liviano, delgado y bello, y que por ello implica cierto sacrificio. Llamaremos "Ideal asceta de alimentación" a este tipo de horizonte utópico.

"sano igual es como algo equilibrado pero no muy denso...si, como igual siempre uno se imagina comidas japonesas, sushi, como un pollo con lechuga, es como la asociación general, o sea, para mí tallarines con salsa no es sano" (Carla).

Estas dos imágenes que se pudieron palpar aparecen en ocasiones juntas y son utilizadas indistintamente, pero en otros casos aparecen relacionadas con situaciones específicas.

En las entrevistas fue fácil constatar que quienes referían las evaluaciones sobre su alimentación mayoritariamente al ideal tradicional de alimentación eran jóvenes que, o ya no vivían con sus padres, o no había nadie en sus casas que se hiciera cargo de su alimentación (porque ambos padres trabajaban, o vivían sólo con uno de ellos que trabajaba, o vivían con una persona de edad que no podía hacerse cargo). En cambio, el ideal asceta de alimentación era una constante, que aparecía con más o menos fuerza según la situación de cada una/o.

Si bien hay bastante claridad sobre lo que entienden por una alimentación ideal, muchas veces no juega un papel importante a la hora de seleccionar lo que se va a comer, dando lugar a situaciones de culpa y tensión en relación a la propia alimentación.

"Yo cuando estoy estresado como que tiendo a comer más, incluso como más "chancho". Cosas que hacen mal. Por ejemplo un completo, una hamburguesa" (Focus Facultad de Filosofía y Humanidades).

\section{b. El orden}

El tipo de alimentos que se consume está en relación muy cercana con la distribución y la forma de ordenar el tiempo, tema que también genera insatisfacción en las y los estudiantes.

Según éstas/os, el ritmo de la universidad de la mano de lo cambiante de las actividades que en ella se realizan genera desordenes como: inapetencia matutina, pues se ha trasnochado y consumido alimentos hasta muy tarde, luego situaciones de hambre incontrolables donde se seleccionan alimentos con alto poder de saciar -como grasas, chocolates, panes-, posteriormente tal vez un ayuno prolongado hasta la hora de regreso al hogar y una vez allí, consumo de alimentos en grandes cantidades.

"estoy tan acostumbrado al ritmo de la universidad que me levanto en la mañana y no tengo hambre, ni medio pan, así... no me dan ganas de comer nada, y cuando llego a mi casa, en la noche, arrazo con el refrigerador, con todo, entonces me cuesta, es una cuestión de... porque en la noche tengo tiempo (Focus Facultad de Artes).

La frecuencia de los desarreglos aumenta en períodos de exámenes o de más exigencia académica, pues el estrés, según cuentan, es una de las razones más potentes a la hora de consumir alimentos considerados no sanos en horarios considerados no convenientes

"Cuando estoy estresado y tengo que estudiar más, como chocolate. Es un mal hábito, pero tiene algo, hay como la necesidad biológica de comerlo" (Focus Facultad Filosofía y Humanidades).

Este tipo de comportamientos fue relatado por varios de los y las estudiantes como fuente de malestar. Frente a esto, algunos optan por generar estrategias de mejora durante la semana y otros optan por reparar los desarreglos durante los fines de semana con la comida casera.

"pienso en el día y es como lo mal que me alimenté y

TABLA 2

Muestra entrevistas en profundidad

\begin{tabular}{|c|c|c|c|c|c|}
\hline Entrevistado $^{2}$ & Sexo & $\begin{array}{l}\text { Carrera/Programa, } \\
\text { Instituto o Facultad }\end{array}$ & $\begin{array}{l}\text { Nivel } \\
\text { socieconómico }\end{array}$ & $\begin{array}{l}\text { Tipo de } \\
\text { régimen }\end{array}$ & $\begin{array}{l}\text { Tipo de } \\
\text { residencia }\end{array}$ \\
\hline Carla & Mujer & Cine/Comunicación e imagen & Medio-alto & Omnívoro & Sola \\
\hline Daniel & Hombre & $\begin{array}{l}\text { Ingeniería en biotecnología } \\
\text { molecular/ciencias }\end{array}$ & Medio-alto & Dieta hipocalórica & $\begin{array}{l}\text { Con padres } \\
\text { y hermanos }\end{array}$ \\
\hline José & Hombre & Psicología/ciencias Sociales & Medio-alto & Ovolactovegetariano & $\begin{array}{l}\text { Con padres } \\
\text { y hermanos }\end{array}$ \\
\hline Ana & Mujer & $\begin{array}{l}\text { Literatura hispánica/ } \\
\text { Filosofía y Humanidades }\end{array}$ & Medio-alto & Omnívoro & Con su madre \\
\hline Aillen & Mujer & Bachillerato/bachillerato & Medio-alto & Vegetariano & Con abuelos \\
\hline Antonio & Hombre & Artes visuales/artes & Medio-alto & Omnívoro & Solo con amigos \\
\hline
\end{tabular}

2 Los nombres de las y los entrevistados han sido reemplazados para resguardar sus identidades. 
es como que ni siquiera me siento energizada por toda el azúcar o todo lo que consumí es como ¡wácala! ¡que asco! Y uno llega el fin de semana con ansias a comer comida de casa, con la mamá, así como todo bien sanito" (Focus Facultad Ciencias Sociales).

Se observa que el orden en la alimentación cumple un papel de importancia y que el desorden genera malestar.

El ingreso a la universidad es identificado por estos/ os jóvenes como el cambio que da inicio a la insatisfacción alimentaria, insatisfacción que toma forma en contraste con los hábitos que tenían durante la educación media, como se expresa en esta cita:

“...comparándome como comía el año pasado, me cuidaba harto, porque hacía ejercicio, me alimentaba bien, era bien cuidadoso con eso. Ahora no, me puse chancho, de hecho yo creo que vivir, además de que en la universidad te sintai mal, ya vivir solo, ya olvídate, todas, todas tus comidas del día son malas" ( Focus Facultad de Artes).

Quienes viven solos/as suelen ser estudiantes que migraron desde otros puntos del país, lo que significa cambios importantes en la vida cotidiana. Cuando se vive sola/o la alimentación es precaria, puesto que la preparación o compra de alimentos compite con otro tipo de actividades que son entendidas como aportes más relevantes. Ellos deben distribuir de manera eficiente sus prioridades monetarias entre la locomoción, fotocopias, libros, alimentos, pago de arriendo y servicios básicos, además del esfuerzo que significa salir de compras para contar con lo necesario para comer y cocinar, como se expresa a continuación:

"Sí dejo de pagar las cuentas o el arriendo me empieza a llamar el dueño y me corta algunos servicios, sí dejo de leer me saco malas notas, pero sí dejo de comer, nadie me molesta, -sí dejo de comer bien-, como igual. Y aunque mi vieja me llame una vez a la semana y me pregunte sí he comido bien" (Focus Facultad Ciencias Sociales)

Cuando se agregan los problemas socioeconómicos, la insatisfacción en torno a la alimentación se torna más aguda. En este tipo de situaciones, las becas alimentarias que se entregan a los estudiantes con problemas económicos suelen ser de gran ayuda ${ }^{3}$.

Quienes viven con algún familiar y tienen una situación económica favorable, de todas maneras están disconformes con su alimentación, lo que atribuyen en principio al mayor acceso y la facilidad de consumo de golosinas, bocadillos salados u otros entre comidas, a la incertidumbre en los horarios de los cursos, entre otras. La insatisfacción es atribuida al hecho de que la alimentación deja de ser un espacio para el disfrute, para convertirse en algo más funcional. Pareciera que es más fácil mantener un orden para este grupo, pues estas personas suelen tener más alimentos frescos como frutas y verduras disponibles en sus casas y comidas elaboradas que pueden transportar a la universidad o comer de regreso. Además, son personas que no deben priorizar sus gastos de manera tan radical como quienes viven solos, pues las opciones son libros, locomoción, comida, salidas.

"Realmente como el ritmo de alimentación que llevo acá es como para que ehh... como para que el cuerpo siga en funcionamiento más que sentarme y disfrutar. Por eso como que no estoy contenta con mi alimentación porque no la disfruto tanto como antes." (Aillen).

\section{c. Lo sano}

Cuando las/los participantes se refieren a lo sano en relación a la alimentación, dan cuenta de aquello que es considerado sano desde los medios masivos de comunicación, en los cuales los criterios médico-nutricionales Ilevan la delantera.

Lo considerado sano es muy parecido, a lo que se ha descrito como alimentación ideal. Lo sano en relación a la alimentación tiene que ver con la calidad de los alimentos y con la manera que se combinan, en qué cantidades y cómo se comen, en qué orden y horarios, como lo que ya se ha presentado en el apartado de alimentación ideal.

Aquí se hará referencia a lo entendido como calidad de los alimentos, en base a lo cual son catalogados como sanos o no sanos.

En la aplicación de esta distinción aparece como transversal que lo sano es lo liviano, lo que es bajo en calorías y no engorda, reafirmando que la ideología médico-nutricional de la que habla Gracia-Arnaiz (3) ha logrado gran preeminencia entre los estudiantes universitarios. Los alimentos considerados sanos por excelencia son las frutas y las verduras, sin embargo, deben combinarse con otros alimentos, carnes en el caso de los omnívoros y frutas secas, legumbres, huevos y leche, si es posible, en el caso de los vegetarianos ${ }^{4}$. Estos últimos consideran que no comer productos animales es sano.

“...porque el vegetariano como no consume carne tiene que estar preocupado de llevar una alimentación más equilibrada. Entonces obviamente están más preocupados de, tratar de comer más legumbres y así a veces vas equilibrando la dieta y es como inconscientemente" (Aillen).

"Combinar hipocalóricos con proteína, carne con verduras. Como te pasaban en el colegio, combinar distintos grupos de alimentos. El triángulo" (Focus Facultad Filosofía y Humanidades).

Las legumbres son consideradas sanas, aunque fueron poco referidas. En relación a las carnes, pareciera haber cierta preferencia por las carnes blancas, a pesar de que el pescado casi no aparece nombrado.

No cualquier preparación es buena pues lo frito es considerado no sano, la ensalada en el caso de los vegetales aparece como la preparación más sana. Las grasas, azúcar y sal son entendidos como no sanos, por lo que todos los alimentos que contengan en exceso alguno de éstos ingredientes también lo serán, lo que incluye las golosinas, las bebidas gaseosas, los cereales industrializados. Lo light, creado para reemplazar alimentos de este tipo, tampoco es considerado sano, pues se desconfía de los edulcorantes o sustitutos.

"claro, como que todas las cosas insanas, muy calóricas, dulces, con exceso de azúcar y grasa" (Focus Ciencias Sociales).

"En el caso de las bebidas, yo no tomo cosas light, porque pienso que hacen más mal que las otras. Hay toda una polémica en torno al light" (Focus Facultad Filosofía y Humanidades).

Tanto el yogur, la leche y la avena son considerados sanos. Alimentos que contienen harinas o las carnes, se consideran sanos siempre que sean consumidos moderadamente.

Lo considerado sano se asemeja mucho a las dietas hipocalóricas, lo que refuerza la idea de que la alimentación sana es tal siempre y cuando, permita y de lugar a lograr o mantener la delgadez.

Toda la gama de alimentos representada por las golosinas, empanadas, completos, hamburguesas, sopaipillas, bebidas,

3 En los años 2008 y 2009 cuando se realizó el trabajo de campo de esta investigación la cobertura de estas becas era muy baja,

lo que es visible en que solo una de las personas entrevistadas era beneficiaria de beca alimentaria.

4 Existen varios tipos de vegetarianos con regímenes más o menos restrictivos en relación al consumo de productos animales. 
café son considerados no sanos y tratados como alimentos sucios, chanchos.

"lo no sano son los panes, los dulces, chocolates (...) O sea, todas las masas, que son plásticas" (Focus Facultad de Artes)

"chanchería es rico: pan con huevo! (...) algo sucio, como un chocolate"(Focus Facultad de Artes)

Este tipo de maneras de referirse a los alimentos fueron utilizados por mujeres, lo que denota que ellas responden a un discurso de lo bello (14), enrolado en las diferencias que el género prescribe a las mujeres, en lo cual lo blanco, es decir, lo limpio, lo higiénico, lo étnicamente deseado, y lo delgado en este caso opuesto a lo chancho, a lo gordo, constituyen valores importantes.

No obstante la clara distinción que los estudiantes realizan sobre lo sano y lo no sano, y siendo que la alimentación ideal incluye lo sano, ellos indican que los alimentos que más se consumen dentro del horario de clases son aquellos que consideran no sanos.

\section{d. El placer}

Actualmente, si bien se han debilitado los marcadores sociales y culturales de saciedad $(15,16)$ debido a la alimentación más bien solitaria regulada individualmente, podemos suponer que el ideal físico de delgadez al que hacíamos alusión funciona como un marcador de saciedad. Hemos ya esbozado la idea de que las personas construyen un ideal alimentario que responde a las consecuencias que se desea que éste tenga sobre el propio cuerpo y es en este contexto que la idea de placer se hace presente.

En primer lugar la alimentación es vivida como algo secundario, que puede ser dejado de lado frente a otros temas. Ello explica por qué muchas veces se prefiere no comer para guardar el dinero para otras cosas, o usar el tiempo de comer en hacer algo que consideran más importante. Cuando se les pregunta sobre la alimentación en varias ocasiones se responde que cumple un papel funcional, es decir, les permite funcionar en la vida diaria, relegándola a un rol mecánico y sin mayores brillos.

No obstante la poca importancia otorgada, cuando se indaga un poco más, afloran temas asociados a la alimentación de gran relevancia. Es aquí cuando vemos que la alimentación puede ser una fuente de malestar o displacer con un papel bastante central en la vida de las personas.

El placer en la alimentación aparece vinculado a varias situaciones. El disfrutar de un momento en familia o con amigos/as o con pareja, y el comer algo considerado sabroso, son algunas de ellas. Estas situaciones de placer pueden fácilmente trastocarse en situaciones de displacer, si se come más de lo que se cree conveniente, y se pierde el control o cuando el alimento es significado como no sano o productor de desorden y con posibilidades de tener consecuencias físicas como subir de peso.

Si bien la idea de comer con placer está presente y además es bien vista, cuando se traspasan ciertos límites y cuando se pierde el control, el comer sólo por placer comienza a resultar problemático. Aquí operaría el imperativo de comer liviano para ser liviano y también la idea del control, en el afán por cumplir con ciertos cánones de belleza vinculados a la delgadez (17)

Es posible hablar de dos tipos de placeres asociados a la alimentación: aquel que se vincula a la ingesta de alimentos que son considerados ricos, que tienen un sabor atractivo, pero que se componen de grasas, azúcar las cuales tienen consecuencias negativas en la percepción del propio cuerpo; y aquel placer que se conecta con el comer sano, liviano y ordenadamente, brindando tranquilidad y con consecuencias positivas para el cuerpo.

Si miramos esto desde la idea del principio de incorporación del que habla Fischler (12), cada tipo de alimentación se traducirá en efectos sobre el imaginario del cuerpo, imprimiéndole las características del alimento en cuestión. Es decir, una alimentación rica en grasas y azúcar, considerada densa, y una liviana, con alto contenido de frutas y verduras y baja en calorías, se traducirán en sensación de pesadez y gordura, y liviandad y belleza respectivamente.

"O sea, como con respecto a la comida, dos tipos de placer, ponte tú, o sea, que están relacionados con la comida... eso, o sea, tú te puedes sentir muy bien por comer sano, pero, no porque te guste comer sano, o sea, sino porque te gusta como te hace sentir comer sano, te hace sentir como una modelo, como que tu vida está cambiando, como me estoy alimentando bien, voy a hacer deportes, hay algo como muy psicológico en eso... eh no sé como más lo podría desarrollar (...) es como un placer orientado más hacia un fin, hacia más largo plazo, como estoy comiendo sano y después voy a ser flaca y cada vez te imaginai más en lo guapa que vas a estar ¿cachai?, en cambio comer rico, te comis todo y senti un placer inmediato como increíble, pero después de eso no te sentí bien contigo misma, te senti como gorda, inflada y que no te podi mover así, pero cuando estai mordiendo esa pizza derretida llena de grasa, es exquisito" (Carla).

Puede entonces suponerse que hay un placer vivido con culpa, con una suerte de pérdida de control, en el cual la ética de la sobriedad y la esbeltez es dejada momentáneamente a un lado y opera como referente frente al cual el comensal está en falta. Y otro placer, más asceta, vinculado a la restricción alimentaria, en la que opera como orientador dicha ética, en donde la liviandad es lo que se vive placenteramente.

Si bien este tipo de discursos aparece tanto en hombres como en mujeres, entre las mujeres se trata de un discurso más elaborado y presente, mientras que en los hombres se habla del comer de más y de comer no sano en términos médico-nutricionales, pero la conexión con el cuerpo propia del principio de incorporación no aparece tan intensamente.

\section{e. Lo tóxico}

Estas dos formas de placer pueden ponerse en movimiento mediante un modelo en el que se incluye lo tóxico y lo no tóxico.

Básicamente se propone que hay un continuo cuyos extremos son la intoxicación y la desintoxicación. La intoxicación se asocia al cansancio y al placer. Se trata de un comportamiento con lógica cortoplacista y va de la mano del consumo de comida considerada no sana. Ingerir alimentos tóxicos y tener comportamientos tóxicos, llevan a que las personas se sientan tóxicas, o como lo dicen ellas, estén tóxicas. Estar tóxico, es consecuencia de la suma de situaciones, como la falta de sueño, la alimentación a base de pan, completos, empanadas, golosinas y el consumo de alcohol.

Frente al estar tóxico sobreviene la necesidad de la desintoxicación. La desintoxicación requiere trabajo y una lógica de largo plazo. Es crucial tener una alimentación considerada sana lo que también incluye el bienestar y el ideal físico. La desintoxicación entonces requiere comer sano y descansar bien.

La intoxicación y desintoxicación son visualizados como episodios intercalados. Los episodios de intoxicación por lo 
general se corrigen o rectifican con episodios y procedimientos de desintoxicación intensiva, con la consecuente modificación temporal, de las situaciones que provocaron el estado que se desea revertir.

La desintoxicación suele atribuirse a una "solicitud del cuerpo", que estaría resentido producto de las falencias por las que pasó.

"...el fin de semana como bien, otras semanas bien, otras mal, son momentos como, de intoxicación, desintoxicación, y decir que hay semanas que, iya! como lo que sea, y otras semanas que me preocupo, al final no se si alguna vez, voy a comer con un plan, de comer siempre lo que se debe. Pero siempre estoy tratando de que no sea tanto" (Focus Facultad de Artes).

"...uno se siente raro, en general, claro como que el peso no me cambia, como que antes comía todos los días en mi casa, ahora acá en la universidad como bien movida, el peso no cambia, pero sí a veces pensai que andai como tóxico, es que tu cuerpo está mal, porque has dormido poco, has comido a deshora, como que has comido mucho de una vez, entonces igual se resiente" (Focus Facultad de Ciencias).

Lo que antes se describió como alimentación no sana - desorden en los horarios y comidas, las grasas, el azúcar y los alimentos altos en calorías- tiene potencial intoxicante, y sería la alimentación ideal o sana la que tendría potencialidad desintoxicante.

Es posible suponer entonces que el uso ordenado del cuerpo permitiría la desintoxicación. Aquí se pone de manifiesto cómo operan los diferentes marcos de sentido en el acto de alimentarse, a saber: la rutinización de las comidas aportaría tranquilidad y seguridad; el comer comida liviana, casera y sana permitiría poner el cuerpo en forma y ajustarse de mejor manera a los modelos de cuerpo y de alimentación ideales. El desorden, la comida pesada, fuera del hogar, con altos contenidos de grasas y azúcar, harían del cuerpo y de sí mismos algo indeseado, lejano a los ideales.

Los marcos de sentido, operarían entones como orientadores a la hora de evaluar la alimentación y tomar decisiones en torno a ésta. Los conceptos aquí descritos serían organizadores de la experiencia alimentaria, por medio de los cuales los individuos irían situándose, y situando sus prácticas de una manera o de otra, dando lugar a combinaciones varias.

\section{DISCUSIÓN}

De los resultados expuestos es posible afirmar que la alimentación en las/los universitarios no resulta ser una fuente de bienestar, sino más bien genera malestares o tensiones. Las/los estudiantes en general, pero más que nada ellas, que participaron de esta investigación tienen una relación bastante compleja con su alimentación y su cuerpo, frente a lo cual sienten placer y culpa, lo que coincide con lo expuesto por Hamblin (18).

En coincidencia con Rivera (19) los jóvenes dicen tener una dieta pobre en frutas, verduras y fibras. No obstante, y a diferencia de lo que señala la investigación de esta autora, esto no se debería a falta de información, pues los discursos coinciden con lo nutricionalmente adecuado, sino que más bien las prácticas responderían a la situación personal de los comensales, el contexto en donde la alimentación tiene lugary a los alimentos disponibles, en donde operarían marcos de sentido que orientarían las decisiones en torno a la alimentación.

Si bien la tensión con respecto a la alimentación es bastante generalizada, el malestar es más profundo entre:

Mujeres ya que experimentan en mayor medida la an- gustia dada por la dificultad para ajustar su alimentación a los ideales y por lo mismo, modelar su cuerpo de manera deseada. Esto coincide con lo afirmado por Lameira et al. (20), sobre la insatisfacción que sienten las mujeres universitarias, más que los hombres universitarios, y con algunos de los resultados de Franch (14).

Personas de nivel socioeconómico bajo, pues tienen menos posibilidades de acceder a aquellos alimentos que son considerados ideales, y con ello a la realización de ciertas prácticas. Esto coincide con lo expuesto por Borges et al. (21), para jóvenes de la ciudad de San Pablo.

Quienes viven solos, pues la incertidumbre frente a la que se encuentran con el ingreso a la universidad, resulta más difícil de manejar, cuando han visto transformada, en muchos aspectos, su vida cotidiana y cuando deben generar nuevas rutinas en varios de ellos. Aquí se coincide con Navarro et al. (22) que afirman que el ingreso a la universidad desmejora la alimentación, sobre todo en quienes dejan de vivir en el seno de la familia.

\section{CONCLUSIONES}

Las apreciaciones sobre la alimentación se ordenan en torno a marcos de sentido de los cuales hemos descrito algunos conceptos clave, a saber: la alimentación ideal, lo sano, el placer y lo tóxico, que permiten identificar malestares asociados a la alimentación de las y los estudiantes.

Las fuentes de malestar asociadas a la alimentación se vincularían a las dificultades que significa el ingreso a la universidad, lo que impediría tener una alimentación más ajustada al ideal que manejan los/las estudiantes. La vinculación entre alimentación y cuerpo es crucial para entender la relación entre alimentación y bienestar, pues mucho del malestar, sobre todo en mujeres, proviene de la tensión que les provoca la construcción de una imagen corporal acorde con sus expectativas. La relación que establecen entre alimentación y bienestar, las/los estudiantes universitarios, es tensa. Tiene características diferentes según género, nivel socioeconómico y tipo de residencia, habiendo insatisfacción y malestar más pronunciado en las mujeres, que viven sin la familia, y que cuentan con menos dinero para sus gastos personales.

\section{RESUMEN}

La alimentación en Chile se ha visto afectada por la "modernidad alimentaria", entendida como la transformación de lo que se come, la forma de producirlo, de distribuirlo, de prepararlo y de consumirlo, producto de un conjunto de procesos vinculados a la industrialización de los alimentos, la mundialización de la economía y la globalización de los medios masivos de comunicación. Esta situación ha generado cambios en los estilos de vida con diferencias sustantivas según el contexto en el que las personas se desenvuelven, la procedencia socio-económica, la edad y el género. La presente investigación realizada entre el 2008 y el 2010, indaga mediante una metodología cualitativa, las percepciones que tienen respecto de su alimentación estudiantes universitarios de Santiago de Chile enfocándose en la relación que establecen con los alimentos que consumen y con su propio cuerpo. Los principales resultados y conclusiones indican que habría insatisfacción respecto de su alimentación en los/las estudiantes universitarios, sobre todo en mujeres, quienes han migrado desde regiones y viven solos/as y quienes cuentan con menos dinero semanal para su gastos personales.

Palabra clave: hábitos alimentarios; percepciones; jóvenes; universidad; malestar. 


\section{BIBLIOGRAFÍA}

1. Ministerio de Salud de Chile (MINSAL). Resultados Encuesta Nacional de Salud 2003. Santiago de Chile, Ministerio de Salud, 2003.

2. Ministerio de Salud de Chile (MINSAL). Encuesta Nacional de Salud ENS 2009-2010. Santiago de Chile, Ministerio de Salud, 2011.

3. Kain, J., Vio, F., Leyton, B., Cerda, R., Olivares, S., Uauy, R., Albala, C. Estrategia de promoción de la salud en escolares de educación básica municipalizada de la Comuna de Casablanca, Chile. Revista Chilena de Nutrición 2005; 32, 2: 466-472. http://www.scielo.cl/scielo.php?pid=S037041062006000500003\&script $=$ sci_arttext (consultado 8-8-07)

4. Gil-Romo, S. , Pérez, E. Vega-Garcia, L. y Romero-Juarez, G. Prácticas alimentarias de mujeres rurales: ¿una nueva percepción del cuerpo?. Salud pública Méx [online] 2007; 49, 1: 52-62. http://www.scielosp.org/scielo.php?script $=s c i$ arttext\&pid=S0036-36342007000100008\&/ng=es\&nrm =iso (consultado 13-2-08).

5. Gracia-Arnaiz, M. 2007. Comer bien, comer mal: la medicalización del comportamiento alimentario. Salud pública Méx. [online]. 2007, 49, 3: 236-242. <http://www. scielosp.org/scielo.php?script=sci_arttext\&pid=S0036$36342007000300009 \& / n g=e s \& n r m=i s o>$. (Consultado 16-8-08).

6. Salinas, J. y Vio, F. Promoción de salud y actividad física en Chile: política prioritaria. Rev Panam Salud Publica 2003; 14, 4: 281-288 http://www.scielosp.org/scielo. php?pid=S1020-49892003000900015\&script=sci_arttext (consultado 5-8-07).

7. Villalobos, P., Rojas, A. y Leporati, M. Chile Potencia Alimentaria: Compromiso con la Nutrición y la Salud de la Población. Rev Chil Nutr 2006; 33, 1: 232-237.http://www.scielo.cl/scielo.php?pid=S071775182006000300004\&script=sci_arttext (consultado 5-8-07).

8. Olivares C, S., Zacarias H, I., Lera M, L. et al. Estado nutricional y consumo de alimentos seleccionados en escolares de la región metropolitana: linea base para un proyecto de promoción del consumo de pescado. Rev Chil Nutr. [online] 2005; 32, 2: 102-108. http:// www.scielo.cl/scielo.php?script=sci_arttext\&pid=S0717$75182005000200004 \& / n g=e s \& n r m=i s o>$ (consultado 13-8-07).

9. Portia, J., Romo, M. Castillo, M.; Castillo-Durán, C.. Las golosinas en la alimentación infantil. Análisis antropológico nutricional. Rev Méd Chile 2004; 132: 1235-1242. http:// www.labnutricion.cl/golosinas.htm (consultada 11-8-07).

10. Díaz, X., Neri D., Daniela, Moraga M., Francisco, Rebollo G., M. Olivares C., S. y Castillo D., C. Análisis comparativo de la canasta básica de alimentos, pirámide alimentaria y recomendaciones nutricionales para preescolares y escolares chilenos. Rev Chil Pediatr 2006; 77, 5: 466-72. http://www.scielo.cl/scielo.php?pid=S037041062006000500003\&script=sci_arttext (consultada el 8-8-07).
11. Fischler, C. El Omnívoro. El gusto, la cocina y el cuerpo. Editorial Anagrama. Barcelona, 1995.

12. Fischler, C. Gastro-nomía y Gatro-anomía. Sabiduría del cuerpo y crisis biocultural. En Jesús Contreras Compilador. Alimentación y Cultura. Necesidades, gustos y Costumbres. Biblioteca de la Universitat de Barcelona, Barcelona, 1995.

13. Canales, M. El grupo de discusión y el grupo focal. En Canales edit. Metodologías de la investigación social. Introducción a los oficios. LOM, Santiago de Chile, 2006.

14. Franch, C. Identidad y prácticas alimenticias: construcción cultural del cuerpo en mujeres de clase de alta de la ciudad de Santiago. Tesis para optar al grado de magíster en estudios de Género, con mención en Ciencias Sociales. Universidad de Chile, Santiago de Chile, 2008.

15. Douglas, M. Las estructuras de lo culinario. En Jesús Contreras Compilador. Alimentación y Cultura. Necesidades, gustos y Costumbres. Biblioteca de la Universitat de Barcelona, Barcelona, 1995.

16. Rozin, P. Perspectivas psicobiológicas sobre las preferencias y las aversiones alimentarias. En Jesús Contreras Compilador. Alimentación y Cultura. Necesidades, gustos y Costumbres. Biblioteca de la Universitat de Barcelona, Barcelona, 1995.

17. Montecino, S. Identidades, mestizajes y diferencias sociales en Osorno, chile: lecturas desde la antropología de la alimentación. Tesis Doctoral. Universiteit Leiden, Leiden, 2006. https://openaccess.leidenuniv.nl/bitstream/1887/4864/1/Thesis.pdf (consultado 10/9/08)

18. Hamblin, D. Actitudes de los adolescentes hacía la comida. En Jesús Contreras Compilador. Alimentación y Cultura. Necesidades, gustos y Costumbres. Biblioteca de la Universitat de Barcelona, Barcelona, 1995.

19. Rivera, M. Hábitos alimentarios en estudiantes de la Universidad Juárez Autónoma de Tabasco. Rev Cubana Salud Pública. [online] 2006; 32, 3:641-9. <http:// scielo.sld.cu/scielo.php?script=sci_arttext\&pid=S0864$34662006000300005 \& / n g=e s \& n r m=i s o>$. (Consultado 11-8-08).

20. Lameira,M., Calado, M.,Rodriguez,Y.,Fernández, M. Hábitos alimentarios e imagen corporal en estudiantes universitarios sin trastornos alimentarios. International Journal of Clinical and Health Psichology 2003; 3, 1, Universidad de Granada, España: 23-33. http://redalyc.uaemex.mx/ redalyc/pdf/337/33730102.pdf (31-8-2009).

21. Borges Neutzling, M., Pavin Araújo, C., Alves VieiraM., Curi Hallal, P. y Baptista Menezes, A. Freqüência de consumo de dietas ricas em gordura e pobres em fibra entre adolescentes. Revista Saúde Pública São Paulo 2007; 41(3): 336-42 http://www.scielosp.org/scielo.php?script=sci_ arttext\&pid=S0034-89102007000300003\&/ng=es\&nrm =iso (consulado 5-8-07).

22. Navarro, S. López, M., Gil, M. Kramer, M., Bueno, M. y Navarro, M. La etapa universitaria como factor de cambio de hábitos saludables. Enfermería 2006; 21:24. Universitat de Barcelona, España: 1-6. http://www.enfermeria21. com/pfw_files/cma/revistas/Educare21/2006/24/aprendiendo2.pdf (31-8-2009). 